\title{
Justification of the Coefficient of Use of the Working Time of the Unit Change for Harrowing Winter Crops with Simultaneous Top Dressing
}

\author{
Alexander Serguntsov ${ }^{1, *}$ and Sergey Lagoda ${ }^{2}$ \\ ${ }^{1}$ Chair of processes and machines in agribusiness, Kuban State Agrarian University named after \\ I.T.Trubilin, 350044, Krasnodar, Russia \\ ${ }^{2}$ Faculty of mechanization, Kuban State Agrarian University named after I.T.Trubilin, 350044, \\ Krasnodar, Russia
}

\begin{abstract}
The dependences of the coefficient of use of the working time of the change of the proposed multifunctional unit for harrowing winter crops with simultaneous additional fertilizing with solid mineral fertilizers are theoretically justified. In the conditions of agriculture of Krasnodar Territory, with an increase in the working speed of the unit, a significant decrease in this coefficient was found for various ruts and capacities of the fertilizer silo. For the proposed unit, all components of the cycle time spent on performing two working and two idle passes through the field with the shuttle method of movement, as well as the number of cycles per shift, the actual duration of the shift time and its utilization rate are calculated. With an increase in the working speed of the unit, all other things being equal, the value of the shift time coefficient decreases.
\end{abstract}

\section{Material and methods of research}

In order to achieve an increase in grain yield, it is necessary to improve the system and methods of tillage, use the most advanced machines. These include multifunctional units (MFUs) and machines. The use of such units and machines will allow the most rational use of capabilities of tractors with constant limits of the working width and working speed [1]. The simplest solution for creating such a MFU and combining several operations into one is to connect two or more single operating tools in a sequence that corresponds to the technological process [2]. If it is necessary, each of its machines can be used as an independent one to perform a specific operation. It is also possible to create a multifunctional unit in another way by placing several working bodies to perform a certain number of technological operations on one common frame $[3,4]$.

\section{Results of research}

We have proposed a new multifunctional unit that combines the operations of fertilizing and simultaneous harrowing of crops [5]. The dependence of the coefficient of time change

\footnotetext{
*Corresponding author: sasha2008_9191@mail.ru
} 
use of the multifunctional unit on its work is necessary to calculate the productivity of such a unit and the need for them (for example: the size of fields, the capacity of the fertilizer hopper), taking into account the change in the working speed, which determines the purpose of this article.

$$
t_{o c}=\frac{2 t_{p}}{n_{r p}},
$$

where $t_{o c}$ - time spent on technological stops of the unit per cycle, h;

$t_{p}$ - duration of stop for filling the tank of the fertilizer hopper, $\mathrm{h} ; t_{p}=0,064 \mathrm{~h}$.

$n_{r p}$ - the number of working passes from refueling to filling the machine with fertilizers.

$$
n_{p n}=\frac{10^{4} V_{b} \lambda \rho}{H B_{a g} L_{r}}
$$

where $V_{b}$ - capacity of the fertilizing hopper, $\mathrm{m}^{3}$;

$\lambda$ - degree of hopper's filling $(\lambda=0,85-0,90)$;

$\rho$ - density of fertilizers, $\mathrm{kg} / \mathrm{m}^{3} \rho=890 \mathrm{~kg} / \mathrm{m}^{3}$;

$H$ - fertilizer application rate, $\mathrm{kg} / \mathrm{ha}$;

$B_{a g}$ - width of the unit's gripping, m;

$L_{r}$ - rut's length, $\mathrm{m}$.

Substituting the obtained data from formula (2) into formula (1), we get:

$$
t_{o c}=\frac{2 \cdot 0,064 \cdot 35 \cdot B_{a g} \cdot L_{r}}{10^{4} \cdot V_{b} \cdot 0,67 \cdot 890}=\frac{4,5 \cdot B_{a g} \cdot L_{r}}{10^{4} \cdot V_{b} \cdot 596},
$$

The cycle time $t_{c}$ is also determined by the well-known dependence [6]:

$$
t_{c}=t_{o c}+t_{r c}+t_{h c},
$$

where $t_{r c}, t_{h c}$ - the time taken for the units to perform two working and two idle passes through the field, respectively, h;

$$
t_{r c}=\frac{2 L_{r}}{1000 V_{r}} \text { и } t_{h c}=\frac{2 l_{h}}{1000 V_{h}},
$$

where $V_{r}$ and $V_{h}$-accordingly, the operating speed of the unit and the idle speed, $\mathrm{km} / \mathrm{h}$ (when working with one mounted device $V_{h}=5 \mathrm{~km} / \mathrm{h}$ ) [6];

$$
l_{h} \text { - idling length of the unit, } \mathrm{km} \text {. }
$$

For the shuttle mode of movement $l_{h}$, it is determined by [6]:

$$
l_{h}=6 R+2 e,
$$

where $R$ - the radius of the unit's turn, $\mathrm{m}$;

$e$ - length of the unit movement, $\mathrm{m}$, including the kinematic length of the tractor (for MTZ-80 in our case $l_{T}=1,2 \mathrm{~m}$ ) and the unit $\left(l_{m}=1,0 \mathrm{~m}\right.$ ).

So, $e=l_{T}+l_{m}=2,2 \mathrm{~m}$.

$$
R=K_{R} \cdot B_{a 2},
$$

where $K_{R}$ - coefficient for calculation of the radius of turn of the unit, $\left(K_{R}=1,0\right)[6]$.

Now from formulas 6 and 7 it follows:

$$
l_{h}=6,0 \cdot 1,0 \cdot B_{a g}+2 \cdot 2,2=6 B_{a g}+4,4,
$$




$$
t_{h c}=\frac{0,002 l_{h}}{V_{h}}=\frac{12 B_{a g}+8,8}{5000},
$$

Substituting the obtained values $t_{r c}$ and $t_{h c}$ into formula 5, we will have the cycle time $t_{c}$ :

$$
t_{u}=\frac{4,5 \cdot B_{a g} L_{r}}{10^{4} \cdot V_{b} \cdot 596}+\frac{2 L_{r}}{1000 \cdot V_{r}}+\frac{12 B_{a g}+8,8}{5000},
$$

The number of cycles per shift (7 hours) is determined by:

$$
n_{c}=\frac{T_{s m}-T_{E T O}-T_{t h i z}}{t_{c}},
$$

where $n_{c}$ - the number of cycles per shift;

$T_{s m}, T_{E T O}, T_{\text {thiz }}$ - accordingly, the normalized shift time ( $T_{s m}=7$ hours), the cost of shift time for carrying out daily maintenance of the tractor and the machine included in the unit, h. $\left(T_{E T O}=0,3+0,17=0,47 \mathrm{~h}\right)[7]$ and on physiological needs $\left(T_{\text {thiz }}=0,30 \mathrm{~h}\right)$.

$$
\begin{aligned}
n_{c}= & \frac{7-0,47-0,3}{\frac{4,5 \cdot B_{a g} L_{r}}{10^{4} \cdot V_{b} \cdot 596}+\frac{2 L_{r}}{1000 \cdot V_{r}}+\frac{12 B_{a g}+8,8}{5000}}= \\
= & \frac{6,23}{\frac{4,5 \cdot B_{a g} L_{r}}{10^{4} \cdot V_{b} \cdot 596}+\frac{2 L_{r}}{1000 \cdot V_{r}}+\frac{12 B_{a g}+8,8}{5000}},
\end{aligned}
$$

The actual duration of the shift time is:

$$
T_{s m}^{d}=T_{r}+T_{h}+T_{E T O}+T_{t h i s}+T_{\text {tehn }},
$$

where $T_{s m}^{d}$ - the actual duration of the shift time, h;

$T_{r}$ - working time of the unit per shift, $\mathrm{h}$;

$T_{h}$ - time for idle turns per shift, $\mathrm{h}$;

$T_{\text {tehn }}$ - downtime of the unit per shift for technological maintenance, $\mathrm{h}$.

In turn, $T_{r}=t_{r c} \cdot n_{c}, T_{h}=t_{h c} \cdot n_{c}, T_{t e h n}=t_{o c} \cdot n_{c}$, тогда

$$
\begin{aligned}
& T_{s m}^{d}=\left(\frac{4,5 \cdot B_{a g} L_{r}}{10^{4} \cdot V_{b} \cdot 596}+\frac{2 L_{r}}{1000 \cdot V_{r}}+\frac{12 B_{a g}+8,8}{5000}\right) \times \\
& \times \frac{6,23}{\frac{4,5 \cdot B_{a g} L_{r}}{10^{4} \cdot V_{b} \cdot 596}+\frac{2 L_{r}}{1000 \cdot V_{r}}+\frac{12 B_{a g}+8,8}{5000}}+0,77+0,3
\end{aligned}
$$

The utilization rate of the working time of the shift is determined by the ratio $T_{r}$ and $T_{s m}^{d}$ :

$$
\tau=\frac{T_{r}}{T_{s m}^{d}}=\frac{t_{r c} \cdot n_{c}}{T_{s m}^{d}}=\frac{2 L_{r} \cdot 6,23}{1000 \cdot V_{r} \cdot 7,3 \cdot\left(\frac{4,5 \cdot B_{a g} L_{r}}{10^{4} \cdot V_{b} \cdot 596}+\frac{2 L_{r}}{1000 \cdot V_{r}}+\frac{12 B_{a g}+8,8}{5000}\right)}=
$$




$$
=\frac{12,46 L_{r}}{7300 \cdot V_{r} \cdot\left(\frac{4,5 \cdot B_{a g} L_{r}}{10^{4} \cdot V_{b} \cdot 596}+\frac{L_{r}}{500 \cdot V_{r}}+\frac{12 B_{a g}+8,8}{5000}\right)},
$$

In Fig. 1, 2, 3, the theoretical dependences of the utilization factor $\tau$ of the MFU shift time on the working speed of the unit movement at different values of the hopper volume and the length of the rut for a rotary hoe with a grip of $6.7 \mathrm{~m}$ are constructed.

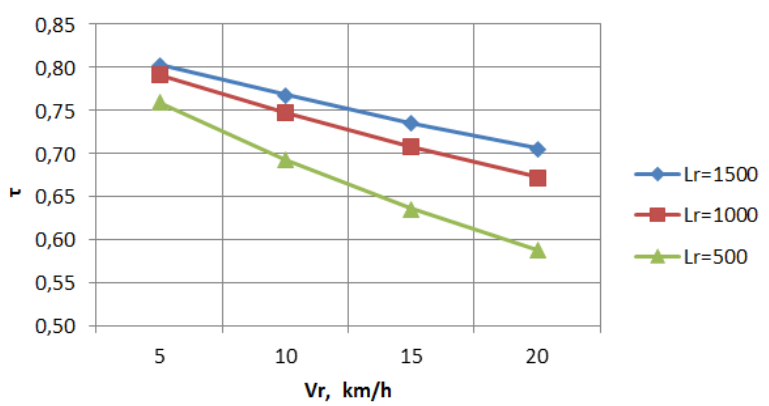

Fig. 1. Dependence $\tau$ on $V_{r}$ at different $L_{r}$

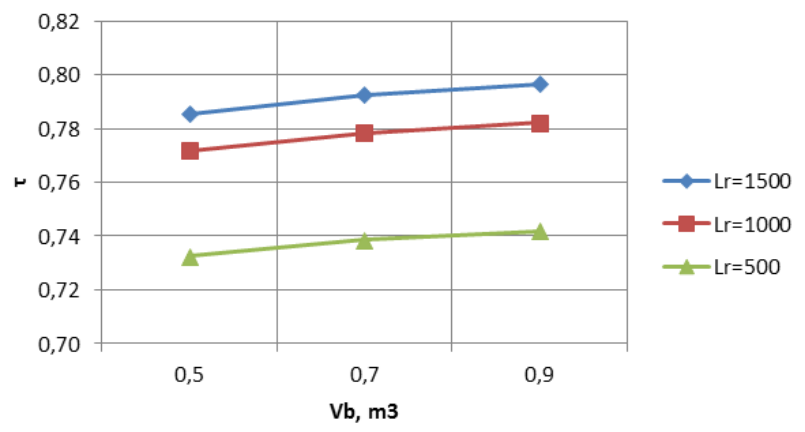

Fig. 2. Dependence $\tau$ on $V_{r}$ and $V_{b}$

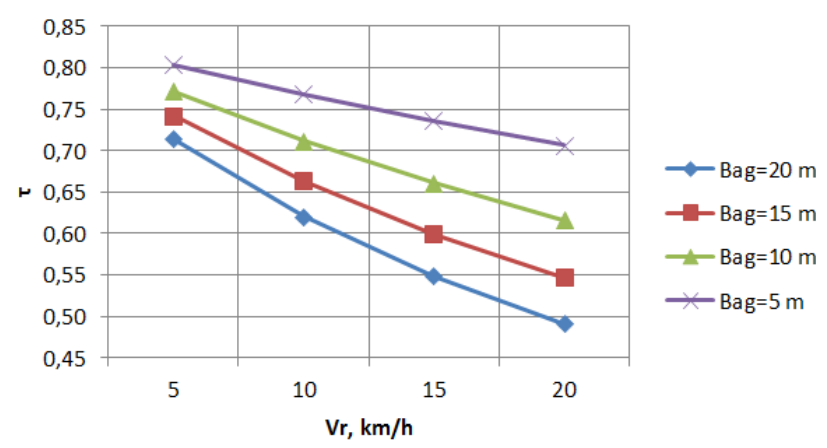

Fig. 3. Dependence $\tau$ on $V_{r}$ and $B_{a g}$ 


\section{Conclusion}

As a result of obtained dependences, it was found that the values of the utilization factor of the working time of the MFU shift for the MTZ-80+MRN-6 unit vary in the range $\tau=0.59$ 0.80 with the length of the rut of 500-1500 m with the hopper $V_{b}=0,7 \mathrm{~m}^{3}$, with the length of the rut of $1000 \mathrm{~m}$ depending on the capacity of the hopper $0.5-0.9 \mathrm{~m}^{3} \tau$ varies in the range of $0.66-0.79$, and with the length of the rut of $1000 \mathrm{~m}$ depending on the width of the grip $\tau$, it changes in the range of $0.49-0.80$.

\section{References}

1. Serguntsov A. Operational parameters and modes of rotary working body for harrowing crops / A. Serguntsov, N. Malashikhin, V. Serguntsova // E3S Web of Conferences. - 2019. - P. 00023.

2. Goryachkin, V.P. Collected works [Text]: in 3 volumes / under edition of N. D. Luchinsky. - M. : Kolos, 1968. - Vol.1 - 720 p.

3. Serguntsov A. Theoretical research of needle-shaped harrow operation expended on soil pinching by needles / A. Serguntsov, V. Serguntsova // E3S Web of Conferences. - 2019. - Vol.126 - P. 00024.

4. Konovalov V. Analytical study of the design parameters of the grinding unit of disk harrows / Konovalov V., Konovalov S., Igumnova V. // B сборнике: IOP Conference Series: Earth and Environmental Science. 12th International Scientific Conference on Agricultural Machinery Industry, INTERAGROMASH 2019. 2019. P. 012086.

5. Ziyazetdinov, R. F. Research of operational processes of units with needle disks for the processing of agricultural crops [Text]: Abstract of $\mathrm{PhD}$ thesis in Engineering. Ufa, 1966. $-26 \mathrm{p}$.

6. Zangiev, A. A. Workshop on the operation of the machine and tractor fleet [Text] / A. A. Zangiev, A. N. Skorokhodov. - M. : Kolos, 2006. - 320 p.

7. Konovalov, V.I. Justification of design parameters of a disk working body with a changing radius of curvature / Konovalov, V.I. // E3S Web of Conferences. - 2020. Vol.193. - P. 01014 